\title{
EXAMINATION OF THE EFFECT OF SODIUM NITRITE ON GAP JUNCTION FUNCTION DURING ISCHAEMIA AND REPERFUSION IN ANAESTHETIZED DOGS
}

\author{
GotTFried MiskolcZi, MÁrton GönCZi, \\ MÁRIA KovÁCs and ÁGNes VÉGH* \\ Department of Pharmacology and Pharmacotherapy, Faculty of Medicine, University of Szeged, \\ Dóm tér 12, H-6721 Szeged, Hungary
}

(Received: July 14, 2016; accepted: September 6, 2016)

\begin{abstract}
It has previously been proved that sodium nitrite, infused prior to coronary artery occlusion or before reperfusion, results in marked antiarrhythmic effect in anaesthetized dogs. We have now examined whether this protection involves the modulation of gap junction (GJ) function by nitric oxide (NO), derived from nitrite administration under ischaemic conditions. Two groups of chloralose and urethane anaesthetized dogs, each containing 13 animals, were subjected to a 25 min period occlusion of the left anterior descending (LAD) coronary artery, followed by reperfusion. One group was infused with sodium nitrite $(0.2 \mu \mathrm{mol} / \mathrm{kg} / \mathrm{min}$, i.v. $)$, the other group with saline $10 \mathrm{~min}$ prior to reperfusion. The severities of arrhythmias and of ischaemia (epicardial ST-segment, total activation time), parallel with changes in myocardial tissue impedance, a measure of electrical coupling of gap junctions, were assessed during the experiments. Compared to the controls, nitrite infusion administered prior to reperfusion significantly attenuated the severity of ischaemia, the ischaemia-induced impedance changes and, consequently, the severity of arrhythmias, occurring during the $1 \mathrm{~B}$ phase of the occlusion, and increase survival following reperfusion $(0 \%$ vs. $85 \%)$. It is concluded that the marked antiarrhythmic effect of sodium nitrite is partly due, to the preservation of the electrical coupling of GJs by NO.
\end{abstract}

Keywords: Arrhythmia - sodium nitrite - gap junction - ischaemia/reperfusion - myocardial tissue impedance

\section{INTRODUCTION}

We have just recently shown that inorganic sodium nitrite, administered in intravenous infusion either before or during a 25 min coronary artery occlusion in anaesthetized dogs, resulted in a marked protection against the ischaemia and reperfusioninduced severe ventricular arrhythmias [14]. We have also pointed out that sodium nitrite was particularly effective, when it was given during the occlusion, but $10 \mathrm{~min}$ prior to reperfusion [14]. In this case, compared with the control group, in which no dog survived the combined ischaemia and reperfusion insult, $92 \%$ of the nitrite received dogs survived [14]. This marked protection was attributed to the generation of nitric oxide (NO) from nitrite. There is now substantial experimental and clinical

*Corresponding author; e-mail address: vegh.agnes@med.u-szeged.hu 
evidence that inorganic nitrate and nitrite, the natural oxidative metabolites of NO, may serve as stores of $\mathrm{NO}[9,10,15,17]$, since they are able to rapidly reduce back to NO, especially under hypoxic or anoxic conditions, when a drop in $\mathrm{pH}$ and oxygen tension promotes reductive processes [30]. This enzyme-independent NO formation may particularly be important during ischaemia, when in the absence of oxygen, the generation of NO by nitric oxide synthase (NOS) becomes limited [10, 30]. Indeed, the infusion of nitrite, even for a short period $(10 \mathrm{~min})$ before reperfusion, markedly increased the plasma nitrate/nitrite (NOx) levels in the coronary sinus blood of the dogs [14]. We concluded that the antiarrhythmic effect of nitrite is associated with better NO availability during ischaemia, and with a subsequent NO-mediated reduction in the harmful consequences of oxidative stress [13], most probably through protein S-nitrosylation and/or S-glutathionylation [14].

There are, however, several other mechanisms, through which nitrite may influence arrhythmia generation. For example, we have shown previously that the antiarrhythmic effect of sodium nitroprusside can be associated with the modulator effect of NO on gap junctional function [6]. There is no doubt that the intercellular connections between cells, called gap junctions (GJs), play an important role in the maintenance of normal impulse propagation, and that the uncoupling of GJs under ischaemic conditions largely contributes to arrhythmia generation, particularly during phase $1 \mathrm{~B}$ $[20,21]$. In contrast to the phase $1 \mathrm{~A}$ arrhythmias, which appear soon after the occlusion (between 3 and $8 \mathrm{~min}$ ), these later occurring phase 1B arrhythmias (around 15 min of the occlusion) are often terminated in sudden cardiac death [21]. The association between the acute ischaemia-induced ventricular arrhythmias and GJs, as well as the influence of arrhythmia generation through the modification of GJs, has already been discussed earlier [22, 24].

Following this line, in the present study we have examined, whether GJs play a role in the marked antiarrhythmic effect of sodium nitrite, infused in dogs during occlusion, but just prior to reperfusion. In this experimental arrangement we have observed a marked protection against the phase 1B arrhythmias, and a high rate of survival in our previous study [14]. ${ }^{1}$

\section{MATERIALS AND METHODS}

The experiments were performed on dogs of both sexes, weighing between 17 and $25 \mathrm{~kg}$ (mean body weight $21 \pm 2 \mathrm{~kg}$ ). The origin and upkeep of the dogs were in accordance with the Hungarian law (XXVIII, chapter IV, paragraph 31) regarding the use of large experimental animals, which conforms to the Guide for the Care and Use of Laboratory Animals (ILAR, 1996), and also conformed to Directive 2010/63/EU of the European Parliament. The protocols were approved by the Ethical Committee for the Protection of Animals in Research of the University of Szeged, Szeged,

\footnotetext{
${ }^{1}$ The arrhythmia data, obtained from 6 control and 6 sodium nitrite treated dogs, were used in this previous paper (KovÁcs et al., 2015).
} 
Hungary (approval number: I-74-5-2012) and by the Department of Animal Health and Food Control of the Ministry of Agriculture and Rural Development (authority approval number XIII/1211/2012).

Before the experiments, the dogs were housed in an animal room (temperature $20{ }^{\circ} \mathrm{C}$; humidity from 40 to $70 \%$; lighting $12 \mathrm{~h}$ per day; two animals per pen) for at least two weeks and fed a standard diet with ad libitum access to water. Food was withdrawn $24 \mathrm{~h}$ before anaesthesia. The surgical procedures were similar to those described previously [23]. In brief, the dogs were lightly anaesthetized with sodium pentobarbitone $(30 \mathrm{mg} / \mathrm{kg}$ i.v.; Sigma, St. Louis, MO, USA) and the right femoral vein was prepared and catheterized for the administration of further anaesthetic (mixture of chloralose and urethane, 60 and $200 \mathrm{mg} \mathrm{kg}^{-1}$, respectively; Sigma, St. Louis, MO, USA) to maintain anaesthesia. The left femoral vein was cannulated for the intravenous administration of sodium nitrite and saline. The depth of anaesthesia was monitored by the examination of the cornea and pain reflexes, as well as by measuring the blood pressure. The animals were then intubated, and ventilated with room air using a Harvard respirator (Harvard Apparatus, Natick, MA, USA) at a rate and volume sufficient to maintain arterial blood gases and $\mathrm{pH}$ within physiological limits [23]. Body temperature was measured from the mid-oesophagus, and maintained by a heating pad at $37 \pm 0.5^{\circ} \mathrm{C}$.

A polyethylene catheter was inserted into the right femoral artery to measure arterial blood pressure (systolic and diastolic). A Millar tip catheter (5F, Millar Instruments, USA) was introduced, via the left carotid artery, into the left ventricle (LV) to detect changes in systolic (LVSP) and end-diastolic (LVEDP) pressures as well as in $\mathrm{LVdP} / \mathrm{dt}$.

Thoracotomy was performed at the fifth intercostal space and the anterior descending branch of the left coronary artery (LAD) was prepared for occlusion just proximal to the first main diagonal branch. Myocardial ischaemia was induced by a $25 \mathrm{~min}$ period occlusion of the $\mathrm{LAD}$, followed by rapid reperfusion. The severity of ischaemia was assessed by measuring changes in total activation time (TAT) and in epicardial ST-segment, using a mapping electrode positioned within the ischaemic myocardial region [6]. Signals were collected from 31 unipolar electrodes (inter-electrode distance; $2 \mathrm{~mm}$ ) at a frequency of $1 \mathrm{kHz}$, stored on a computer and analyzed offline by creating activation and ST maps. Changes in epicardial activation were assessed as a time delay between the first and a last point activated under the electrode and expressed as the total activation time (TAT) in milliseconds. Elevations of epicardial ST-segment, recorded in each minute from the unipolar electrodes, were averaged and expressed in $\mathrm{mV}$.

The electrical coupling of gap junctions was assessed by measuring tissue impedance $^{2}$ as described in detail previously $[6,19,20]$. In brief, four stainless steel electrodes, mounted on a non-conductive panel, were inserted into the left ventricular

${ }^{2}$ Since the myocardial tissue is not purely resistive (the cell membrane contains capacitance elements), there will be a time delay between the voltage ( $V$ measured across the tissue) and the sinusoidal current (I) applied through it. Therefore, myocardial impedance $(Z=V / I)$ can be precisely defined by two com- 
wall within the proposed ischaemic myocardial area. A sub-threshold alternating current $(10 \mu \mathrm{A}, 8 \mathrm{kHz})$ was applied through the outer pair of electrodes, and voltage was measured between the inner electrode pair using a lock-in amplifier (SR830 DSP; Stanford Research Systems, CA, USA). Changes in resistivity (in Ohm.cm) and in phase angle (in ${ }^{\circ}$ ) were recorded by a computer with an acquisition time of $4 \mathrm{~s}$ and plotted at 1 min intervals. To eliminate small oscillations, resulting from ventilation, five consecutive $4 \mathrm{~s}$ measures were averaged at each minute.

Ventricular arrhythmias during a $25 \mathrm{~min}$ coronary artery occlusion and following reperfusion were assessed according to the Lambeth Conventions [27] with that modification as has been previously outlined [23]. Thus we determined the total number of ventricular premature beats (VPBs), the incidence and the number of episodes of ventricular tachycardia (VT), and the incidence of ventricular fibrillation (VF) during the occlusion period. During reperfusion, only the incidence of VF, which is a fatal event in this species, was determined. Dogs that were alive 5 min after reperfusion were considered to be survivors.

All parameters, together with a chest lead electrocardiogram, were measured with a Plugsys Haemodynamic Apparatus (Hugo Sachs Electronics, Germany) and recorded on a Graphtec Thermal Array Recorder (Hugo Sachs Electronics, Germany).

\section{Experimental protocol}

A total of 26 dogs were used and randomly divided into two groups. Each animal was subjected to a 25 min LAD occlusion followed by rapid reperfusion. Control dogs (C; $n=13$ ) were infused with saline, commencing $10 \mathrm{~min}$ prior to the end of the coronary artery occlusion. In the other group $\left(\mathrm{NaNO}_{2}-\mathrm{PR} ; n=13\right)$ sodium nitrite was administered by intravenous infusion at a concentration of $0.2 \mu \mathrm{mol} \mathrm{kg}^{-1} \mathrm{~min}^{-1}$ also $10 \mathrm{~min}$ prior to reperfusion as has been described previously [14]. In dogs that survived the combined ischaemia and reperfusion insult, the hearts were stopped with an overdose of the anaesthetic either within 2 min (where myocardial tissue samples were taken) or $5 \mathrm{~min}$ (where the area at risk was determined). In dogs that suddenly fibrillated on reperfusion, the heart was quickly excised when the fibrillation had been observed. In 7 control and 7 nitrite treated dogs, after excising the heart, the risk area was assessed by injecting Patent Blue $\mathrm{V}$ dye into the re-occluded artery using the same method that has been described in detail elsewhere [23].

ponents: tissue resistance $(R)$ and phase angle $(\theta)$. In tissues, the impedance $(Z)$ is a complex number $(Z=R+j X)$, where $R$ is the resistance (in phase component of $V$ with respect to $I), j$ is the imaginary unit $(j=\sqrt{-1})$, and $X$ is the reactance (in quadrate component of $V$ with respect to $I$ ). The time delay between the voltage and current waves can be determined from the phase angle $[\theta=\arctan (X / R)]$ of tissue impedance. 


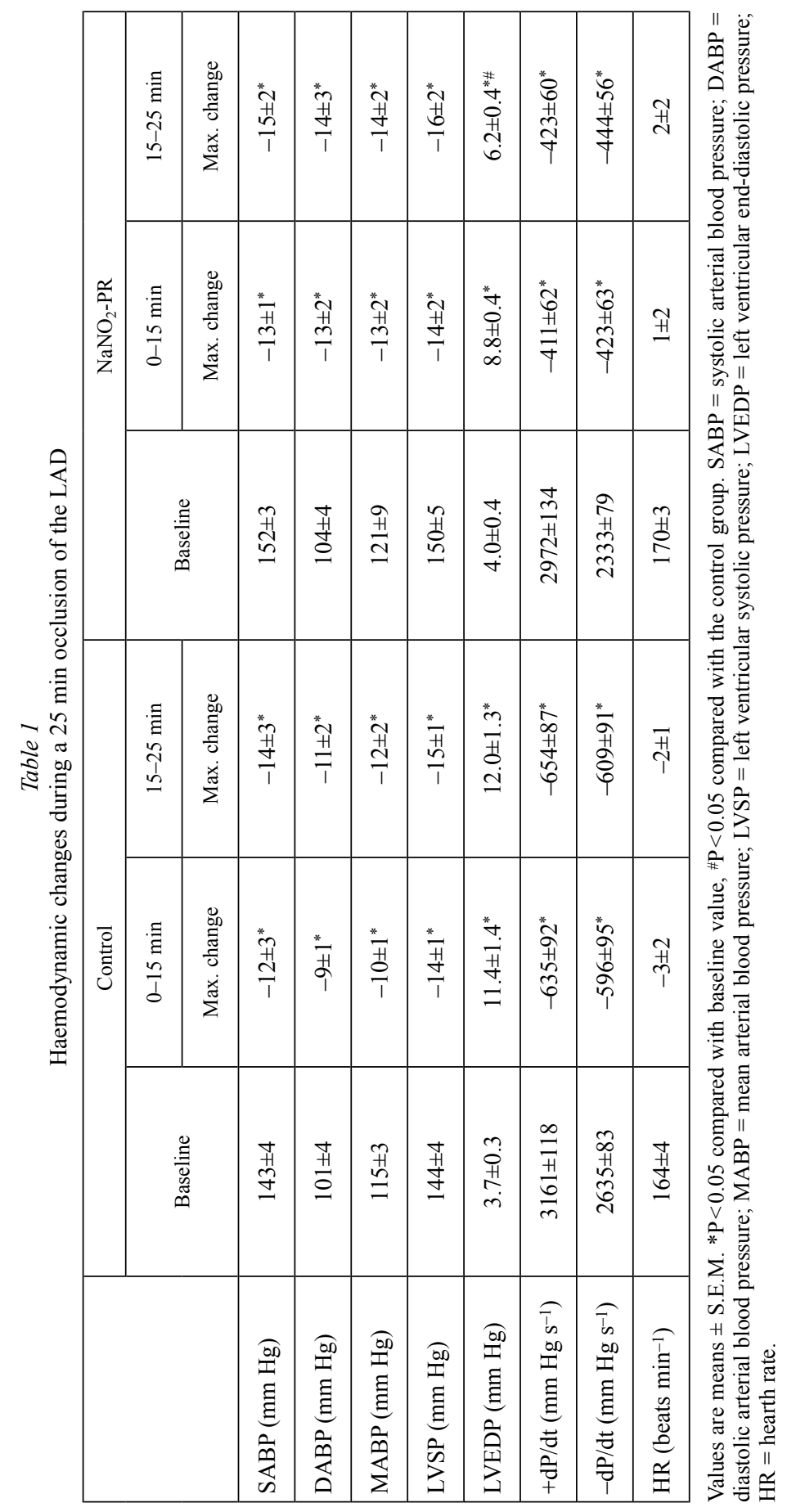

Acta Biologica Hungarica 68, 2017 

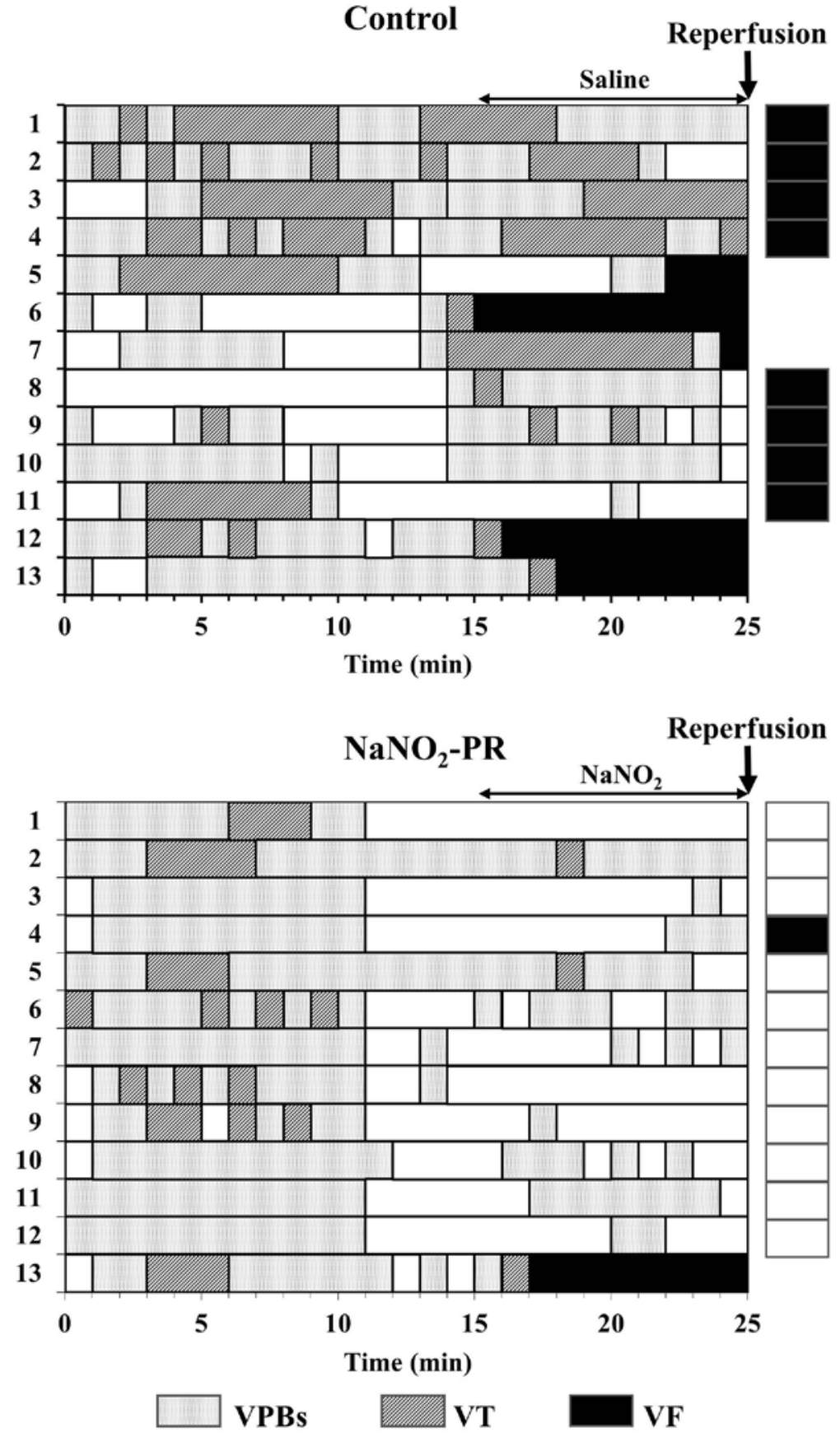
Fig. 1. The distribution of arrhythmia events following a 25 min occlusion and reperfusion of the LAD in 13 control and 13 sodium nitrite-treated dogs. The filled columns represent ventricular fibrillation (VF), the shaded columns show periods of ventricular tachycardia (VT) and the lightly stippled columns are periods during which ventricular premature beats (VPBs) were evident. VF on reperfusion is shown by the black horizontal columns, and this was the only arrhythmia event assessed during reperfusion. In control dogs there were many VPBs and episodes of VT over the entire occlusion period, and in $5 / 13$ dogs VF occurred during the 1B phase of the occlusion. Since, all the dogs that survived the occlusion, fibrillated on reperfusion, there was no survivor in this group from the combined occlusion and reperfusion insult. Sodium nitrite infused 10 min prior to reperfusion reduced the number of VPBs and VT episodes during phase 1B. In this group VF occurred in one dog during the occlusion, and in one dog following reperfusion, and 11 dogs out of the 13 animals survived reperfusion

\section{Statistical analysis}

All data are expressed as means \pm S.E.M. and the differences between means were compared by ANOVA for repeated measures and by the one-way ANOVA as appropriate, using the Fisher post-hoc test. VPBs and episodes of VT were compared using the Kruskal-Wallis test. The incidences of arrhythmias (such as VT and VF) and survival from the combined ischaemia and reperfusion insult were compared by the Fisher's exact test. Differences between groups were considered significant at $P<0.05$.

\section{RESULTS}

\section{Haemodynamic changes following a 25 min occlusion of the LAD}

These are summarized in Table 1. Occlusion of the LAD resulted in marked and similar decreases in arterial blood pressure, left ventricular systolic pressure (LVSP), positive and negative $d P / d t_{\max }$, and increases in LVEDP in both groups during the first $15 \mathrm{~min}$ of ischaemia. In dogs infused with sodium nitrite $10 \mathrm{~min}$ prior to reperfusion, there were no further significant alterations in the haemodynamic parameters compared to the saline treated controls, except that the LVEDP significantly reduced by the end of the occlusion period. The heart rate in anaesthetized dogs was practically unchanged both during occlusion and following sodium nitrite administration.

\section{The severity of ventricular arrhythmias during coronary artery occlusion and reperfusion}

The distribution and the incidence of various types of arrhythmias are illustrated in Figure 1. In control dogs subjected to a 25 min occlusion of the LAD, there were many ectopic beats $(525 \pm 90)$ and episodes of VT $(19.8 \pm 5.6)$ that occurred $92 \%$ 

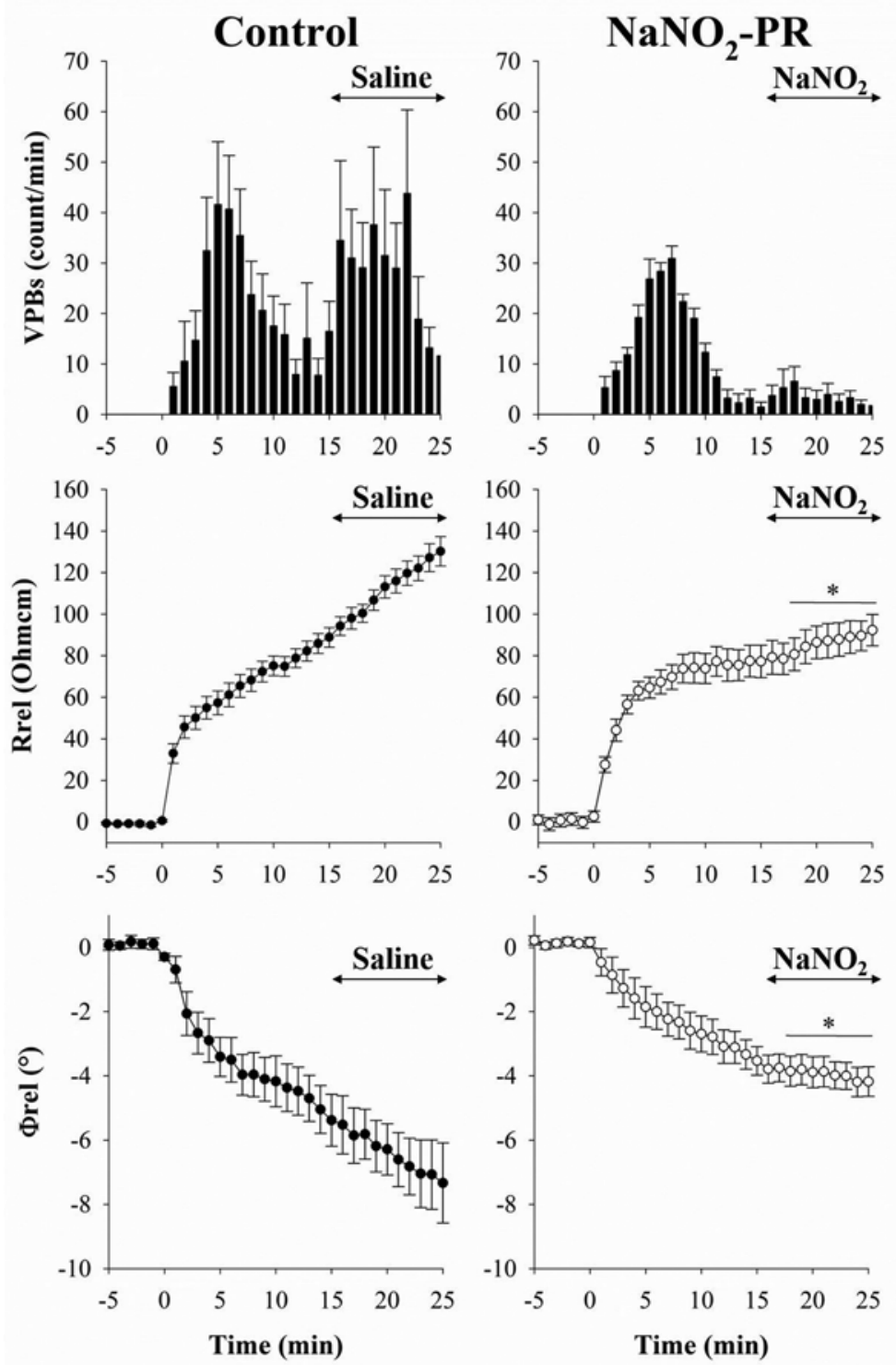

Fig. 2. Distribution of VPBs and relative changes in tissue impedance (resistivity and phase angle) at one minute intervals over a 25 min occlusion of the LAD occlusion in control dogs and in dogs infused with sodium nitrite $10 \mathrm{~min}$ prior to reperfusion. The infusion of nitrite significantly reduced the number of VPBs occurring during phase 1B, and inhibited the second steep rise in tissue resistivity, as well as the decline in phase angle that was obvious in the controls between 15 and $25 \mathrm{~min}$ of the ischaemia. Values are means \pm S.E.M. $* P<0.05$ compared to the controls 

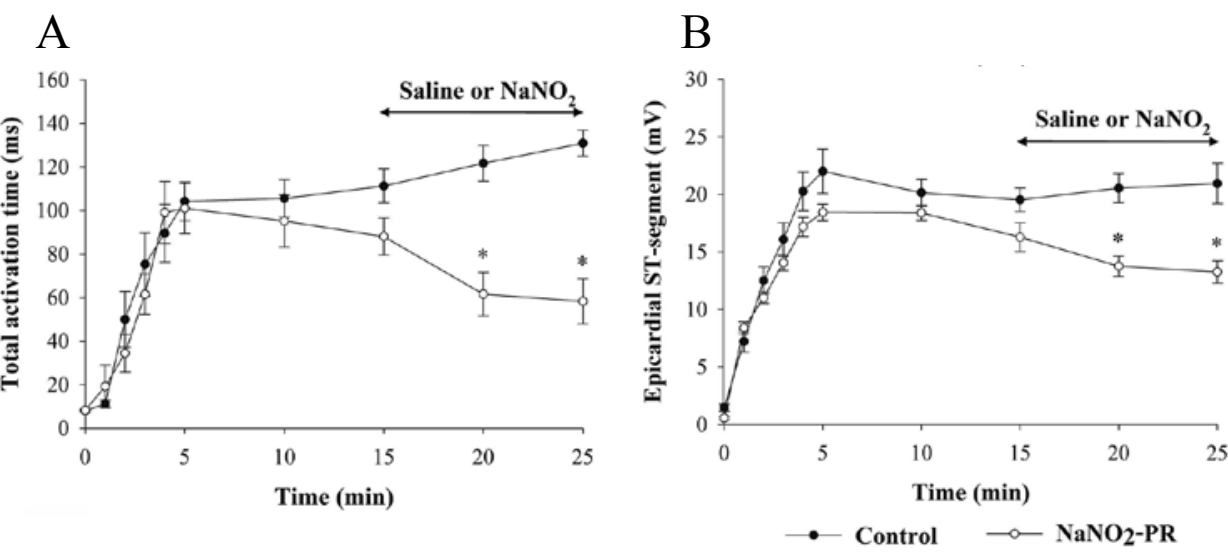

Fig. 3. Changes in the epicardial ST-segment (A) and in the total activation time (B) during a 25 min occlusion of the LAD in control and nitrite infused dogs. In control animals both indices of ischaemia severity were markedly increased especially during the initial $5 \mathrm{~min}$ of the occlusion. These ischaemic changes were significantly reduced after the infusion of sodium nitrite. Values are means \pm S.E.M. $* P<0.05$ compared to the controls

of the dogs. Furthermore, in this group 5 out of the 13 animals (38\%) exhibited VF during occlusion and all the remaining dogs $(62 \%)$ died in VF following reperfusion, thus no control dog survived the combined ischaemia and reperfusion insult. In contrast, dogs infused with sodium nitrite $10 \mathrm{~min}$ prior to reperfusion showed significantly less VPBs and episodes, particularly during the later phase of the occlusion. Although in this group one dog $(8 \%)$ died during the occlusion period and another one (8\%) when the myocardium was reperfused, $85 \%$ of the animals infused with sodium nitrite survived the combined ischaemia and reperfusion challenge (Fig. 1).

\section{Distribution of VPBs and changes in tissue impedance during a 25 min LAD occlusion}

The data are shown in Figure 2. In control dogs occlusion of the LAD resulted in an immediate increase in tissue resistivity and a decrease in phase angle accompanied by the occurrence of many ectopic beats. These changes were apparent during the first 10 min of ischaemia (phase 1A), after which the impedance changes became slower and the number of VPBs significantly decreased. A second steeper rise in resistivity and decline in phase angle started around $13 \mathrm{~min}$ of the occlusion, followed immediately by the re-appearance of the phase $1 \mathrm{~B}$ arrhythmias. In dogs that received sodium nitrite, the resistivity and the phase angle changes during phase $1 \mathrm{~A}$ were similar to the controls, although incidentally the phase $1 \mathrm{~A}$ arrhythmias (Figs 1,2) were somewhat less pronounced in the nitrite treated than in the control animals. Nevertheless, in this 
group, the infusion of sodium nitrite almost completely inhibited the ischaemiainduced marked impedance changes, and significantly suppressed the ectopic activity, which was apparent in the controls during phase 1B.

\section{Changes in epicardial ST-segment and total activation time during LAD occlusion}

We used two indices to assess the severity of ischaemia during coronary artery occlusion; i.e. the changes in total activation time (TAT; Fig. 3A) and in epicardial ST-segment (Fig. 3B). In control dogs occlusion of the LAD resulted in immediate and marked increase in both parameters, reaching the maximum values within the first $5 \mathrm{~min}$ of the occlusion. The infusion of sodium nitrite $10 \mathrm{~min}$ prior to reperfusion resulted in an immediate decrease in the epicardial ST-segment and in the TAT, and these were significantly less pronounced by the end of the occlusion period than in the controls.

\section{Area at risk}

There were no significant differences in the area at risk between the control $(n=7$; $36 \pm 2 \%)$ and sodium nitrite $(n=7 ; 37 \pm 3 \%)$ groups.

\section{DISCUSSION}

We have previously provided evidence that in dogs gap junctions play an important role in the generation of arrhythmias that accompany the sudden occlusion of one of the main branches of the left coronary artery, and that preconditioning by modifying the function of gap junctions may exert the protection against these severe ventricular arrhythmias $[19,20,24]$. We have also reported that nitric oxide (NO), which plays a mandatory role, both as trigger and mediator of the preconditioning-induced early and delayed antiarrhythmic protection $[1,11,25,26]$, attains its protective effect, among the others, through the modification of gap junctions $[6,22]$. Since we have just recently published that the inorganic sodium nitrite, infused in dogs prior to and during the entire occlusion period, or just prior to reperfusion, results in marked antiarrhythmic effect [14], we have now examined whether this considerable protection is due, at least in part, to the regulation of gap junction function by NO, derived from sodium nitrite. It should be noted that the present study involves 6 control and 6 treated dogs, of which the arrhythmia data, but not the results of the impedance measurements, had already been included in a previous publication [14]. In the present study 7 new control and 7 sodium nitrite-treated animals were added, in order to precisely assess the relationship between gap junctions and the sodium nitriteinduced antiarrhythmic effect. 
It was found that sodium nitrite, administered just that period of the occlusion when the phase 1B arrhythmia events are expected (i.e. around $15 \mathrm{~min}$ ), resulted in immediate haemodynamic effects (e.g. a decrease in LVEDP), a reduction in ischaemia severity (epicardial ST-segment and total activation time), abolished the ischaemia-induced steep impedance changes, and simultaneously, suppressed the severe ventricular arrhythmias, occurring during phase 1B.

At least three conclusions can be drawn from these findings. First, the effect of nitrite is almost immediate, indicating a rapid conversion of nitrite to NO under ischaemic conditions $[4,28,30]$. We assume that by the time of the commencement of the infusion (i.e. $15 \mathrm{~min}$ of the occlusion) the ischaemic changes are sufficiently advanced to provide a milieu (low $\mathrm{pH}$ and oxygen tension) for the reduction of nitrite to NO. This assumption is supported by the finding that the plasma NOx levels (indicator of NO formation) in the blood of the coronary sinus were markedly increased following nitrite infusion [14]. Since the plasma nitrate level was unchanged during nitrite infusion, we assume that nitrite, under these reductive conditions, most probably converted to NO [14].

Second, the short period of nitrite administration during ischaemia but prior to reperfusion can effectively increase NO bioavailability. This usually decreases following coronary artery occlusion, since in the absence of oxygen, the generation of NO from NOS activation, is reduced or even abolished [12]. Thus under such conditions, replacement of NO, for example, by an enzyme-independent source, may reduce the ischaemic changes and the occurrence of arrhythmias during the rest of the ischaemia. The increased NO bioavailability, resulted from a short period of sodium nitrite infusion prior to reperfusion, may favourably affect the reperfusion-induced severe ventricular arrhythmias, such as ventricular fibrillation, which is common in this canine model when the coronary artery is suddenly reopened [23]. We have found that only one nitrite-treated dog out of the remaining 12 dogs fibrillated during reperfusion in contrast with the controls, in which all the dogs that survived the occlusion died in VF on reperfusion. These findings are in accordance with the results of Gonzalez et al. [5], who showed also in dogs that infusion of nitrite during the last $5 \mathrm{~min}$ of ischaemia, significantly reduce the infarct size and improve the recovery of contractile function after reperfusion. One of the mechanisms, which may play a role in the protection against the reperfusion-induced injury, is the suppression of the generation of oxidative stress products. There is substantial evidence that NO can regulate the production of reactive oxygen species (ROS) during ischaemia and reperfusion $[3,7,12]$. For example, we have shown previously that the increase of NO bioavailability during ischaemia by either preconditioning or the administration of an NO donors, suppresses the reperfusion-induced ROS generation and the arrhythmias [12]. Similarly, we have found that sodium nitrite, regardless of the duration of infusion, significantly suppressed the superoxide and peroxynitrite production during reperfusion [14].

Third, the results of the present study confirm our hypothesis that NO, among its several other effects as discussed in detail elsewhere [e.g. 12, 14, 24], may influence 
cardiac gap junctions and thereby modify the generation of the ischaemia and reperfusion-induced severe ventricular arrhythmias $[6,22]$. The effect of NO derived from sodium nitrite on gap junction channels is also immediate, since after the commencement of the infusion the second steep rise in resistivity and decline in phase angle were absent (the changes of these parameters after $15 \mathrm{~min}$ of ischaemia remained virtually constant), and the ectopic activity during phase 1B was considerable suppressed. This finding suggests that the infusion of sodium nitrite, just at a time of the occlusion period, when the serious, often life-threatening phase 1B arrhythmias start to appear, is able to inhibit the generation of these arrhythmias, and this effect can be associated with the preservation of gap junctions by NO. Although it is still not known whether opening or closing of gap junctions by NO leads to the antiarrhythmic protection, our electrical impedance measurements suggest that sodium nitrite inhibits the further uncoupling of gap junctions, since it abolished those steep impedance changes that had preceded the occurrence of the phase 1B arrhythmias. Although we are aware that the measurement of impedance changes only provide indirect evidence for the opened/closed status of gap junctions, since a substantial portion of gap junctions needs to be closed to detect changes in tissue resistivity [8], we assume that NO, derived from sodium nitrite, keeps open, rather than close gap junction channels. The assessment of the phosphorylation of connexin $43(\mathrm{Cx} 43)$, the main structural protein of gap junctions, would provide further information about the open/closed status of these channels. There is a consensus that the phosphorylated form of $\mathrm{Cx} 43$ can be associated with the open form of the channel, whereas a dephosphorylated form indicates the closure of gap junctions [2]. In the present study we did not determine connexin phosphorylation, since we know that the ischaemia-induced dephosphorylation of this protein rapidly recovers following reperfusion, but we have previous evidence that NO, released, for example, from sodium nitroprusside, keeps $\mathrm{Cx} 43$ in phosphorylated form and the gap junctions in opened state during ischaemia [6].

The other consequence of the rapid release of NO from sodium nitrite during ischaemia is the marked protection against the reperfusion-induced severe ventricular arrhythmias. The reduction in VF during reperfusion is particularly pronounced, resulting in a high rate of survival $(85 \%)$ in the nitrite treated group. As to whether this marked protection against the reperfusion-induced VF is associated with a direct effect of NO on gap junctions occurring during reperfusion we do not know, since it is difficult to measure the impedance changes soon after reperfusion, when VF commonly occurred particularly in control dogs. However, it is more than likely that the outcome of reperfusion, and thus the severity of reperfusion-induced arrhythmias, largely depends on the severity of the antecedent ischaemia, we assume that the nitrite-induced less severe ischaemic changes and the suppression of arrhythmias during phase $1 \mathrm{~B}$, via the modulation of gap junctions, may contribute to the better survival of these animals from the combined ischaemia and reperfusion insult. Gonzalez et al. [5] proposed that administration of nitrite just prior to reperfusion might have a particular clinical value, as adjunctive pharmacological therapy to coronary angioplasty interventions, by improving myocardial salvage, and consequently, by providing a better cardiac function following reperfusion of an acute myocardial ischaemic 
insult [5]. We have now confirmed these findings and provided further evidence that nitrite by modulating gap junctions may protect the heart against the ischaemia and reperfusion-induced severe, life-threatening ventricular arrhythmias.

In conclusion, the present study provides evidence that NO, deriving from molecules which readily release $\mathrm{NO}$, protects the heart against the acute ischaemia and reperfusion-induced severe, often fatal rhythm disturbances. Although other effects, such as the preservation of endothelial function [16] or the favourable haemodynamic (e.g. the reduction in preload [LVEDP], and consequently in myocardial stretch) and anti-aggregator abilities of NO donors, cannot be excluded, as indirect factors, from the antiarrhythmic effect of sodium nitrite, the prompt inhibition of the impedance changes and, almost in parallel, the suppression of the phase 1B arrhythmias that occur immediately after the administration of sodium nitrite, suggest a direct modulator effect of $\mathrm{NO}$ on gap junctions. As to whether this involves the NO-induced increase in myocardial cGMP and a resultant decrease in the intracellular calcium level [18], which directly modulates gap junctions during ischaemia [29], or whether nitrite, through protein S-nitrosylation (e.g. S-nitrosylation of connexin43) result in modification in gap junction structure and/or function, warrants further investigations.

\section{ACKNOWLEDGEMENTS}

This work was supported by the Hungarian Scientific Research Foundation (OTKA; Project number K105252). We are also grateful to the excellent technical assistance of Erika Bakó and Irene Biczók.

\section{REFERENCES}

1. Babai, L., Szigeti, Z., Parratt, J. R., Végh, Á. (2002) Delayed cardioprotective effects of exercise in dogs are aminoguanidine sensitive: possible involvement of nitric oxide. Clin. Sci. 102, 435-445.

2. Beardslee, M. A., Lerner, D. L., Tadros, P. N., Laing, J. G., Beyer, E. C., Yamada, K. A. et al. (2000) Dephosphorylation and intracellular redistribution of ventricular connexin 43 during electrical uncoupling induced by ischemia. Circ. Res. 87, 656-662.

3. Burwell, L. S., Brookes, P. S. (2008) Mitochondria as a target for the cardioprotective effects of nitric oxide in ischemia-reperfusion injury. Antioxid. Redox. Signal 10, 579-599.

4. Duranski, M. R., Greer, J. J., Dejam, A., Jaganmohan, S., Hogg, N., Langston, W. et al. (2005) Cytoprotective effects of nitrite during in vivo ischemia-reperfusion of the heart and liver. J. Clin. Invest. 115, 1232-1240.

5. Gonzalez, F. M., Shiva, S., Vincent, P. S., Ringwood, L. A., Hsu, L. Y., Hon, Y. Y. et al. (2008) Nitrite anion provides potent cytoprotective and anti-apoptotic effects as adjunctive therapy to reperfusion for acute myocardial infarction. Circulation 117, 2986-2994.

6. Gönczi, M., Papp, R., Kovács, M., Seprényi, Gy., Végh, Á. (2009) Modulation of gap junctions by nitric oxide contributes to the antiarrhythmic effect of sodium nitroprusside. Br. J. Pharmacol. 156, 786-793.

7. Iwase, H., Robin, E., Guzy, R. D., Mungai, P. T., Vanden Hoek, T. L., Chandel, N.S. et al. (2007) Nitric oxide during ischemia attenuates oxidant stress and cell death during ischemia and reperfusion in cardiomyocytes. Free Radial. Biol. Med. 43, 590-599. 
8. Jongsma, H. J., Wilders, R. (2000) Gap junctions in cardiovascular disease. Circ. Res. 86, 1193-1197.

9. Kevil, C. G., Lefer, D. J. (2011) Review focus on inorganic nitrite and nitrate in cardiovascular health and disease. Cardiovasc. Res. 89, 489-491.

10. Kevil, C. G., Kolluru, G. K., Pattillo, C. B., Giordano, T. (2011) Inorganic nitrite therapy: historical perspective and future directions. Free Radical Biol. Med. 51, 576-593.

11. Kis, A., Végh, Á., Papp, J. Gy., Parratt, J. R. (1999) Repeated cardiac pacing extends the time during which canine hearts are protected against ischaemia-induced arrhythmias: role of nitric oxide. J. Mol. Cell. Cardiol. 31, 1229-1241.

12. Kiss, A., Juhász, L., Seprényi, Gy., Kupai, K., Kaszaki, J., Végh, Á. (2010) The role of nitric oxide, superoxide and peroxynitrite in the anti-arrhythmic effects of preconditioning and peroxynitrite infusion in anaesthetized dogs. Br. J. Pharmacol. 160, 1263-1272.

13. Kohr, M. J., Sun, J., Aponte, A., Wang, G., Gucek, M., Murphy, E. et al. (2011) Simultaneous measurement of protein oxidation and S-nitrosylation during preconditioning and ischemia/reperfusion injury with resin-assisted capture. Circ. Res. 108, 418-426.

14. Kovács, M., Kiss, A., Gönczi, M., Miskolczi, M., Seprényi, Gy., Kaszaki, J., Kohr, M., Murphy, E., Végh, Á. (2015) Effect of sodium nitrite on ischaemia and reperfusion-induced arrhythmias in anaesthetized dogs: Is protein S-nitrosylation involved? Plos One 24; 10: e0122243.

15. Lefer, D. J. (2006) Nitrite therapy for protection against ischemia-reperfusion injury. Am. J. Physiol. Renal Physiol. 290, F777-F778.

16. Lefer, D. J., Nakanishi, K., Vinten-Johansen, J. (1993) Endothelial and myocardial cell protection by a cysteine-containing nitric oxide donor after myocardial ischaemia and reperfusion. J. Cardiovasc. Pharmacol. 22, S34-S43.

17. Lundberg, J. O., Carlström, M., Larsen, F. J., Weitzberg, E. (2011) Roles of dietary inorganic nitrate in cardiovascular health and disease. Cardiovasc. Res. 89, 525-532.

18. Méry, P. F., Pavoine, C., Belhassen, L., Pecker, F., Fishcmeister, R. (1993) Nitric oxide regulates cardiac $\mathrm{Ca}^{2+}$ current. Involvement of cGMP-inhibited and cGMP-stimulated phosphodiesterases through guanylyl cyclase activation. J. Biol. Chem. 268, 26286-26295.

19. Miskolczi, G., Gönczi, M., Kovács, M., Seprényi, Gy., Végh, Á. (2015) Further evidence for the role of gap junctions in the delayed antiarrhythmic effect of cardiac pacing. Can. J. Physiol. Pharmacol. 93, 545-553.

20. Papp, R., Gönczi, M., Kovács, M., Seprényi, Gy., Végh, Á. (2007) Gap junctional uncoupling plays a trigger role in the antiarrhythmic effect of ischaemic preconditioning. Cardiovasc. Res. 74, 396405.

21. Smith, W. T., Fleet, W. F., Johnson, T. A., Engle, C. L., Cascio, W. E. (1995) The 1b phase of ventricular arrhythmias in ischemic in situ porcine heart is related to changes in cell-to-cell electrical coupling. Circulation 92, 3051-3060.

22. Végh, Á., Gönczi, M., Miskolczi, G., Kovács, M. (2013) Regulation of gap junctions by nitric oxide influences the generation of arrhythmias resulting from acute ischemia and reperfusion in vivo. Frontiers in Pharmacology 4, 76-82.

23. Végh, Á., Komori, S., Szekeres, L., Parratt, J. R. (1992) Antiarrhythmic effects of preconditioning in anaesthetised dogs and rats. Cardiovasc. Res. 26, 487-495.

24. Végh, Á., Papp, R. (2011) Possible mechanisms of the acute ischemia-induced ventricular arrhythmias: the involvement of gap junctions. In: Tripathi, O. N., Ravens, U., Sanguinetti, M. C. (eds) Heart Rate and Rhythm. Molecular Basis, Pharmacological Modulation and Clinical Applications, Springer-Verlag, Berlin Heidelberg, pp. 525-543.

25. Végh, Á., Papp, J. Gy., Parratt, J. R. (1994) Prevention by dexamethasone of the marked antiarrhythmic effects of preconditioning induced $20 \mathrm{~h}$ after rapid cardiac pacing. Br. J. Pharmacol. 113, 1081-1082.

26. Végh, Á., Szekeres, L., Parratt, J. R. (1992) Preconditioning of the ischaemic myocardium; involvement of the L-arginine - nitric oxide pathway. Br. J. Pharmacol. 107, 648-652. 
27. Walker, M. J. A., Curtis, M. J., Hearse, D. J., Campbell, R. W. F., Janse, M. J., Yellon, D. M., Cobbe, S. M., Coker, S. J., Harness, J. B., Harron, D. W. G., Higgins, A. J., Julian, D. G., Lab, M. J., Manning, A. S., Northover, B. J., Parratt, J. R., Riemersma, R. A., Riva, E., Russell, D. C., Sheridan, D. J., Winslow, E., Woodward, B. (1988) The Lambeth Conventions: guidelines for the study of arrhythmias in ischaemia, infarction, and reperfusion. Cardiovasc. Res. 22, 447-455.

28. Webb, A., Bond, R., McLean, P., Uppal, R., Benjamin, N., Ahluwalia, A. (2004) Reduction of nitrite to nitric oxide during ischemia protects against myocardial ischemia-reperfusion damage. Proc. Natl Acad. Sci. USA 101, 13683-13688.

29. White, R. L., Doeller, J. E., Verselis, V. K., Wittenberg, B. A. (1990) Gap junctional conductance between pairs of ventricular myocytes is modulated synergistically by $\mathrm{H}^{+}$and $\mathrm{Ca}^{++}$. J. Gen. Physiol. 95, 1061-1075.

30. Zweier, J. L., Wang, P., Samouilov, A., Kuppusamy, P. (1995) Enzyme-independent formation of nitric oxide in biological tissues. Nature Medicine 1, 804-809. 